\title{
Cerebral oximetry monitoring during aortic arch aneurysm replacement surgery in Jehovah's Witness patient -A case report-
}

\author{
Seong-Hyop Kim, Tae-Gyoon Yoon, Tae-Yop Kim, Hae-Kyoung Kim, and Woo-Sung Sung* \\ Department of Anesthesiology and Pain Medicine, Konkuk University School of Medicine, Seoul, *Department of Anesthesiology and \\ Pain Medicine, Masan Samsung Hospital, Sungkyunkwan University School of Medicine, Masan, Korea
}

Anesthetic management for aortic arch aneurysm (AAA) surgery employing deep hypothermic circulatory arrest in a Jehovah's Witness (JW) patient is a challenge to anesthesiologist due to its complexity of procedures and their refusal of allogeneic transfusion. Even in the strict application of intraoperative acute normovolemic hemodilution (ANH) and intraopertive cell salvage (ICS) technique, prompt timing of re-administration of salvaged blood is essential for successful operation without allogeneic transfusion or ischemic complication of major organs. Cerebral oximetery $\left(\mathrm{rSO}_{2}\right)$ monitoring using near infrared spectroscopy is a useful modality for detecting cerebral ischemia during the AAA surgery requiring direct interruption of cerebral flow. The present case showed that $\mathrm{rSO}_{2}$ can be used as a trigger facilitating to find a better timing for the re-administration of salvaged blood acquired during the AAA surgery for JW patient. (Korean J Anesthesiol 2010; 58: 191-196)

Key Words: Aortic arch aneurysm, Cerebral oximetry, Jehovah's Witness

Because aortic arch aneurysm (AAA) surgery employing cardiopulmonary bypass (CBP) and deep hypothermic cardiac arrest (DHCA) is highly associated with massive intraoperative hemorrhage [1], a transfusion of allogeneic banked blood is required to maintain oxygen-delivery and coagulation function. However, since Jehovah's witness (JW) patients refuse allogeneic transfusions due to their religious beliefs, intraoperative maintenance of these functions during AAA surgery in JW patients becomes complicated [2,3]. Acute normovolemic hemodilution (ANH) and intraoperative cell salvage (ICS) have been introduced for managing these patients. While blood retrieved from the ICS (ICS-blood) process can simply be reinfused with the ICS device, the blood retrieved from the ANH (ANH-blood) procedure can be collected only during the early phase of surgery, and its volume is very limited. Therefore, the timing and volume of ANH-blood administered should be carefully determined; early consumption of ANH-blood will make it difficult to contain the coagulation dysfunction during the later part of surgery and could easily be associated with additional hemorrhage. In contrast, insufficient or delayed infusion of ANH-blood may lead to excessive hemodilution resulting in compromised oxygen-delivery capacity and the risk

Received: August 21, 2009. Revised: 1st, September 15, 2009; 2nd, September 25, 2009. Accepted: October 6, 2009.

Corresponding author: Tae-Yop Kim, M.D., Ph.D., Department of Anesthesiology and Pain Medicine, Konkuk University School of Medicine, Hwayang-dong, Gwangjin-gu, Seoul 143-729, Korea. Tel: 82-2-2030-5445, Fax: 82-2-2030-5449, E-mail: pondkim@unitel.co.kr CCThis is an open-access article distributed under the terms of the Creative Commons Attribution Non-Commercial License (http:// creativecommons.org/licenses/by-nc/3.0/), which permits unrestricted non-commercial use, distribution, and reproduction in any medium, provided the original work is properly cited. 
for hypoxic injury. Strategies should be considered that focus the timing of ANH-blood administration around the time after weaning the patient from the CBP or around the end of the surgery, instead of during the mid-stage of the surgery.

Monitoring regional cerebral oxygen saturation $\left(\mathrm{rSO}_{2}\right)$ with near-infrared spectroscopy mid-surgery is closely related to changes in intraoperative hemoglobin $(\mathrm{Hb})$ levels and can be used as a transfusion trigger [4,5]. Intraoperative $\mathrm{rSO}_{2}$ monitoring facilitates clinical outcome and is useful to monitor cerebral ischemia during cardiac surgery $[6,7]$. In addition to monitoring lactate and mixed venous oxygen saturation $\left(\mathrm{SvO}_{2}\right)$, $\mathrm{rSO}_{2}$ monitoring provides information regarding the cerebral oxygen supply/consumption balance during the procedure of interrupting cerebral blood flow during AAA surgeries in JW patients and may be useful for determining the timing of intraoperative ANH-blood administration.

We used $\mathrm{rSO}_{2}$ monitoring to help identify the appropriate time for reinfusing the limited volume of retrieved ANH- and ICS-blood. Then, we supplied the appropriate volume of blood at the appropriate times to prevent cerebral ischemia. We had successful anesthetic management and herein present the case.

\section{Case Report}

A saccular aneurysm $(5.3 \times 4.7 \times 5.0 \mathrm{~cm})$ was discovered in the rising portion of the left carotid artery in a 36 -year-old male JW (height, $170 \mathrm{~cm}$; weight, $70 \mathrm{~kg}$ ) (Fig. 1). The aneurysm caused a compression of the left (lt.) innominate artery, lt. internal carotid artery (ICA), and lt. subclavian artery (SCVA), as well as stenosis in the lt. ICA (stenosis length, $2.4 \mathrm{~cm}$ ), so a replacement AAA surgery was performed. At admission, blood taken before the surgery showed a hematocrit (Hct) of $32 \%$, albumin of 3.2 $\mathrm{g} / \mathrm{dl}$, and platelets of $270,000 / \mathrm{mm}^{3}$. For a 3 day minimum, erythropoietin (EPO) was administered to enhance hemostasis before the elective surgery. However, in the repeated imaging tests, we found that the size of the AAA had suddenly increased so the surgery could not be delayed. We preceded with the emergent surgery $8 \mathrm{~h}$ after a single subcutaneous injection of 42,000 U EPO.

On the operating table, we began intraoperative monitoring including electrocardiography, blood pressure (BP), pulse oximeter $\left(\mathrm{SpO}_{2}\right)$, end-tidal $\mathrm{CO}_{2}$, bispectral index, and temperature (nasophagryngeal and rectal temperature). The $\mathrm{rSO}_{2}$ sensor (Invos ${ }^{\mathrm{TM}}$, Cerebral/Somatic Oximeter 5100C, Somanetics, Troy, MI, USA) was attached to the bilateral forehead. A right (rt.) radial artery cannula was placed to monitor continuous $\mathrm{BP}$, arterial pressure waveform-derived cardiac output (APCO), and stroke volume variation (SVV). We performed a targetcontrolled infusion of propofol and remifentanil, administered rocuronium, and performed an endotracheal intubation. After inducing anesthesia, we placed an invasive BP monitor in the lt. radial artery and lt. femoral artery (FA). A large-bore (9 Fr) central venous catheter (LB-CVC, AVA $^{\mathrm{TM}}$, Edward Lifesciences, Irvine, CA, USA) and a pulmonary artery catheter was placed in the rt. internal jugular vein. Before surgery, we started monitoring continuous cardiac output, pulmonary artery pressure (PAP), central venous pressure (CVP), and $\mathrm{SvO}_{2}$. We placed a transesophageal echocardiography (TEE) probe and started TEE monitoring. The coagulation function was monitored by thromboelastometry (Rotem ${ }^{\mathrm{TM}}$, Pentapharm, Basel, Switzerland). For the ANH procedure, three closed-loops consisting of three-way stopcocks, intravascular lines, and three bags of citrate phosphate dextrose (CPD) were connected to the LBCVC. All loops were filled with normal saline, and continuous flow was maintained. Blood was withdrawn by gravity for the ANH. Hydroxyethylstarch (6\% HES, Voluven ${ }^{\mathrm{TM}}$, Fresenius-Kabi,

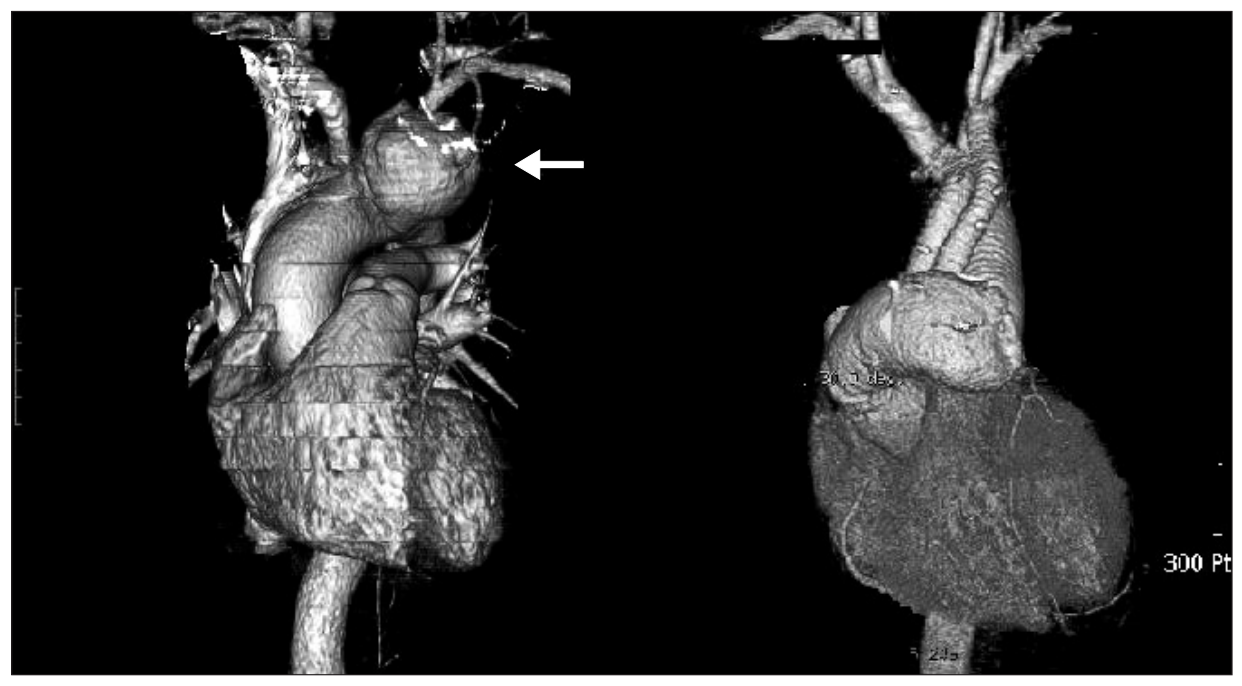

Fig. 1. Computed tomographic imaging of aortic arch aneurysm. A saccular aneurysm $(5.3 \times 4.7 \times 5.0 \mathrm{~cm})$ was found in the arising portion of the aortic arch's left carotid artery and it caused a compression of left innominate artery, left internal carotid artery, and left subclavian arter). It also produced a stenosis of left internal carotid artery (stenosis length $2.4 \mathrm{~cm}$ ). 
Homborg, Germany) of the same volume was administered at the same rate of withdrawal. ANH (500 ml each bag, 1,500 $\mathrm{ml}$ total) was retrieved and administered very slowly $(<600$ $\mathrm{ml} / \mathrm{h}$ ) to maintain patient-bag-patient continuity. All blood hemorrhaged during the operation was retrieved using a cell salvage device (Cell Saver $6^{\mathrm{TM}}$, Haemonetics, Braintree, MA, USA). The 225-ml centrifugal container was activated in the automatic mode; each time $150 \mathrm{ml}$ of ICS-blood was retrieved and reinfused.

Over the first half of the surgery, phenylephrine (0.01$0.05 \mathrm{mcg} / \mathrm{kg} / \mathrm{min}$ ) was continuously administered to treat hypotension and vasodilation and to avoid excessive fluid administration resulting in red blood cell (RBC) dilution and worsening of the platelet and coagulation factors. When a low $\mathrm{rSO}_{2}$ ( $<50 \%$ of normal body temperature) was observed despite administration of ICS blood and increased phenylephrine, the ANH blood infusion rate was increased to restore $\mathrm{rSO}_{2}$ (Fig. 2), and then returned to maintenance speed immediately.

For the CBP, a cannula was placed in the rt. auxiliary artery (RAxA), FA, and superior and inferior vena cavas. After administering heparin ( $3 \mathrm{mg} / \mathrm{kg}$ ), the activated clotting time was maintained for more than $400 \mathrm{~s}$. A bloodless priming solution of 1,900 $\mathrm{ml}$, consisting of $100 \mathrm{ml}$ of $5 \%$ albumin, $100 \mathrm{ml}$ of $20 \%$ mannitol, $500 \mathrm{ml}$ of $6 \%$ HES, and the remaining crystalloid solution, was used to activate the CBP. Before CBP activation, 1,000 ml of HES and $800 \mathrm{ml}$ of crystalloid solution were administered simultaneously to compensate for hypovolemia due to ANH. All blood loss from the hemorrhaging during surgery was retrieved entirely by ICS. We also administered 100,000 U of a urinary trypsin inhibitor (Ulistin ${ }^{\mathrm{TM}}$, Hanlim, Seoul, Korea).

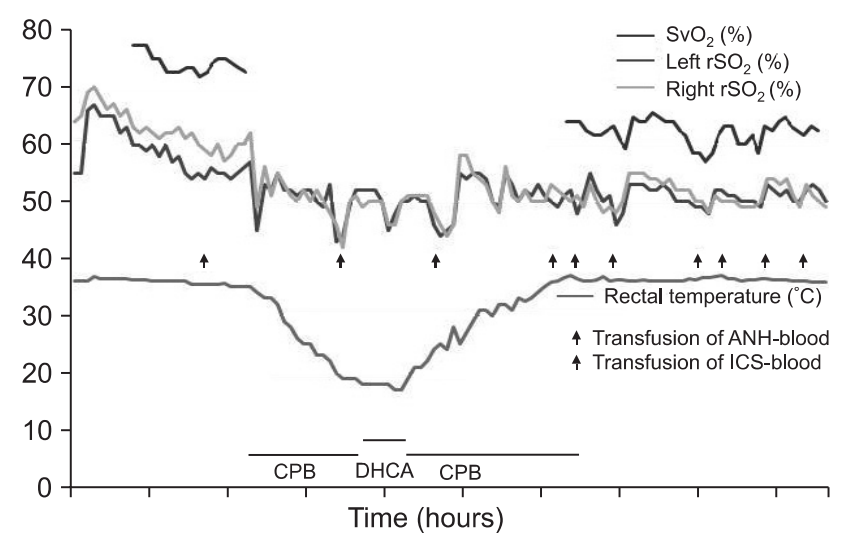

Fig. 2. Schema of the intraoperative changes in cerebral oximetry and the timing of the autologous blood transfusion. $\mathrm{SvO}_{2}$ : mixed venous $\mathrm{O}_{2}$ saturation, $\mathrm{rSO}_{2}$ : cerebral $\mathrm{O}_{2}$ saturation measured by near infrared spectroscopy, ANH-blood: blood salvaged by acute normovolemic hemodilution, ICS-blood: blood salvaged by intraoperative cell-salvage procedure, CPB: cardiopulmonary bypass, DHCA: deep hypothermic circulatory arrest.
During CBP, the mean BP was maintained at $60-70 \mathrm{mmHg}$, body temperature was lowered to $18^{\circ} \mathrm{C}$, and tranexamic acid ( $2 \mathrm{~g}$ ) was added to the CBP circuit. After reaching the target temperature, $500 \mathrm{mg}$ of thiopental was administered and DHCA was performed for the AAA replacement procedure.

First, the proximal part of the lt. carotid artery (LCA) and lt. SCA were clamped and excised, the excised proximal part of the clamp was anastomosed to the prepared synthetic graft, and

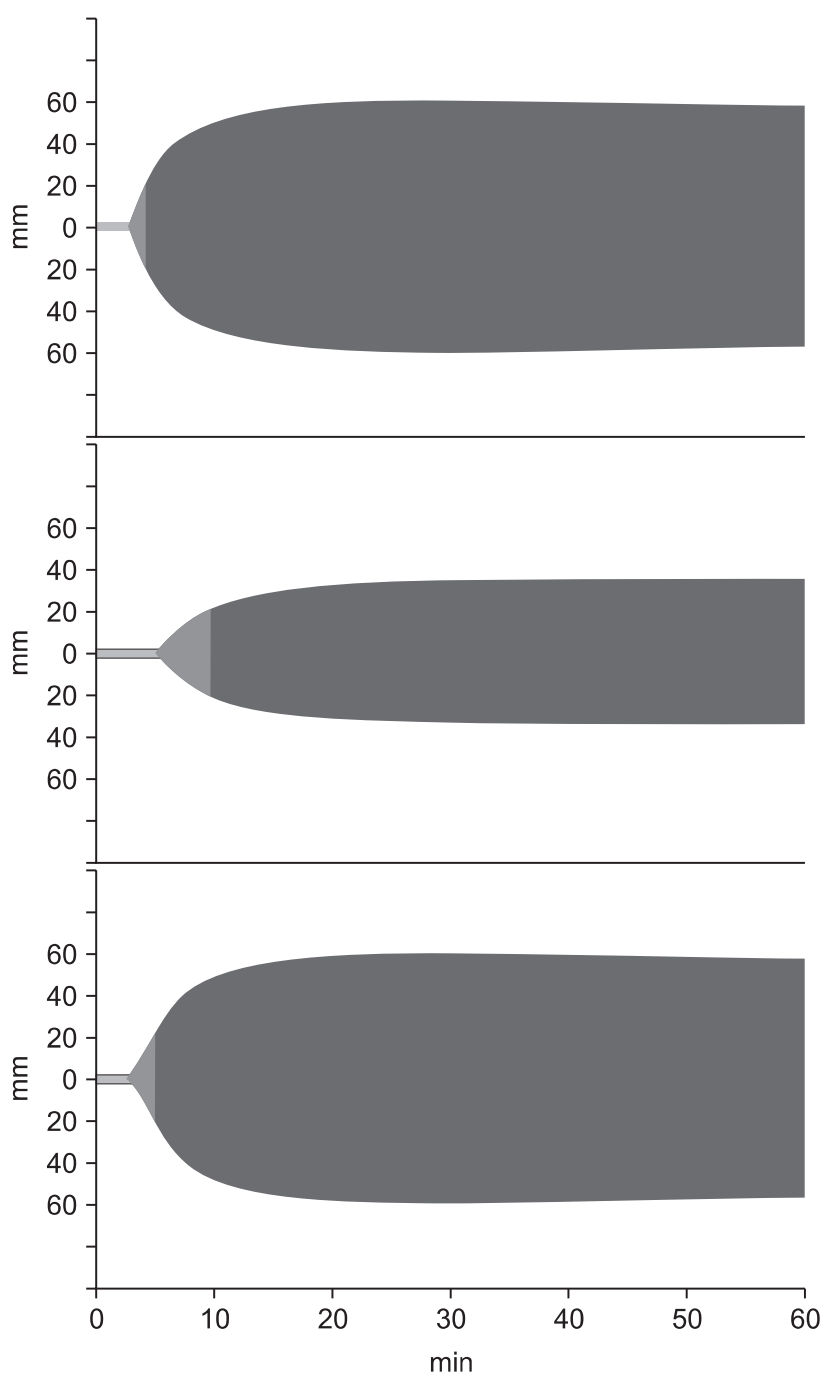

Fig. 3. Tracings of intra-operative coagulation profile using thromboelastometry $\left(\right.$ Rotem $^{\mathrm{TM}}$ ). Top: tracing after the acute normovolemic hemodilution before the initiation of cardiopulmonary bypass. Middle: tracing at $30 \mathrm{~min}$ after the initiation of cardiopulmonary bypass. Bottom: tracing after the administration of protamine for heparin-reversal during post-bypass period. All tracings were made using heparinase cup (HEPTEM in Rotem ${ }^{\mathrm{TM}}$ system) to remove the heparin's effect on coagulation function. Reaction time, $\alpha$-angle, were within normal range in all stages. But, the maximal amplitude at $30 \mathrm{~min}$ after the initiation of cardiopulmonary bypass was mildly reduced from the reference value indicated by dotted line. 
the clamp was released. The proximal and distal parts of the AAA and the rising part of the rt. brachiocephalic arterial trunk (RBCA) were clamped simultaneously. With 70-80 $\mathrm{mmHg}$ pressure on both the RAxA and FA, the CBP flow was refused after removal of the AAA, and both ends of the synthetic graft were quickly anastomosed. The anastomosis was completed between the clamped part of the RBCA and the synthetic graft branch. Then, the clamp at the proximal anastomosis of the AAA was released. After a $20 \mathrm{~min}$ interruption of cerebral flow, the FA-synthetic graft and both ICA connections were completed, cerebral perfusion was initiated, and the rewarming process was immediately started. Once the clamped ascending aorta was connected to the clamped distal anastomosis of the synthetic graft, both clamps were released, and normal systemic-cerebral circulation was completed. In addition to the priming solution, HES (500 ml) was also administered during the $3 \mathrm{~h}$ of CBP. If $\mathrm{rSO}_{2}$ decreased, the infusion rate of the vasoconstrictor was increased and the oxygen flow to the CPB oxygenator was reduced. At $60 \mathrm{~min}, \mathrm{rSO}_{2}$ was reduced below 50\%, $150 \mathrm{~min}$ after the start of CBP, despite the reduction in oxygen flow, and 200 and $300 \mathrm{ml}$ of ANH blood were administered (Fig. 2). After $3 \mathrm{~h}$ of CBP, the TEM showed a normal coagulation profile (Fig. 3).
Normal body temperature recovered, the patient was weaned from CBP, the hemodynamics were well maintained, and the heparin was neutralized with protamine. After CBP weaning, $20 \%$ mannitol $(100 \mathrm{ml}), 5 \%$ albumin $(100 \mathrm{ml})$, HES $(2,000$ $\mathrm{ml})$, crystalloid solution $(500 \mathrm{ml})$ (Plasmasol ${ }^{\mathrm{TM}}, \mathrm{CJ}$, Seoul, Korea), and 2,800 ml of salvaged ICS blood was administered. Nevertheless, when $\mathrm{rSO}_{2}$ was less than $50 \%$, the remaining ANH-blood was re-administered in $360 \mathrm{ml}, 300 \mathrm{ml}$, and 300-ml fractions, respectively, to maintain the $\mathrm{rCbO}_{2}$ above $50 \%$. After CBP, $300 \mathrm{ml}$ of crystalloid was administered considering the excreted urine volume.

Over the $9 \mathrm{~h}$ of surgery, urine volume was maintained at 1,500 $\mathrm{ml}$ and $1-2 \mathrm{ml} / \mathrm{kg} / \mathrm{h}$. The estimated blood loss was $3,500 \mathrm{ml}$. The TEM coagulation profile prior to the end of the surgery was normal, and the Hct was $25 \%$.

The patient was transferred to the intensive care unit with patient-controlled analgesia and stable hemodynamic and coagulation function. The Hct was $26 \% 6 \mathrm{~h}$ after the surgery and $25 \%$ at the extubation ( $36 \mathrm{~h}$ after surgery). The Hct was $31 \%$ when the patient was moved to the general ward 4 days after the surgery. He experienced no signs of neurologic complications and was discharged (Table 1).

Table 1. Perioperative Changes of Blood Chemistry Analysis

\begin{tabular}{|c|c|c|c|c|c|c|c|c|c|c|c|c|c|}
\hline & \multirow{2}{*}{ Preop } & \multicolumn{2}{|c|}{ Pre-CPB } & \multicolumn{3}{|c|}{ СРB } & \multicolumn{3}{|c|}{ Post-CPB } & \multicolumn{4}{|c|}{ Postop } \\
\hline & & $1 \mathrm{~h}$ & $2 \mathrm{~h}$ & $1 \mathrm{~h}$ & $2 \mathrm{~h}$ & $3 \mathrm{~h}$ & $1 \mathrm{~h}$ & $2 \mathrm{~h}$ & $3 \mathrm{~h}$ & $1 \mathrm{D}$ & $2 \mathrm{D}$ & $3 \mathrm{D}$ & $4 \mathrm{D}$ \\
\hline Hct (\%) & 32 & 32 & 33 & 22 & 17 & 18 & 20 & 23 & 25 & 26 & 25 & 28 & 31 \\
\hline Albumin (g/dl) & 3.0 & & & & & & & & & 2.3 & 2.9 & 2.8 & 3.8 \\
\hline PT (sec) & 16.8 & & & & & & & & & 17.8 & & 12.2 & 18.7 \\
\hline PT INR & & & & & & & & & & 1.53 & 1.31 & 1.27 & \\
\hline APTT (sec) & 16.8 & & & & & & & & & 50.8 & 49.8 & 44.4 & \\
\hline $\mathrm{pH}$ & 7.49 & 7.47 & 7.48 & 7.47 & 7.52 & 7.42 & 7.52 & 7.49 & 7.457 & 7.478 & 7.46 & 7.48 & \\
\hline $\mathrm{PaCO}_{2}(\mathrm{mmHg})$ & 29.4 & 33 & 33 & 34 & 30 & 33 & 33 & 32 & 37 & 29.3 & 31.0 & 31.2 & \\
\hline $\mathrm{PaO}_{2}(\mathrm{mmHg})$ & 95 & 247 & 262 & 313 & 388 & 290 & 279 & 265 & 246 & 196 & 144 & 121 & \\
\hline $\mathrm{HCO}_{3}{ }^{-}(\mathrm{mEq} / \mathrm{L})$ & 22.5 & 21.1 & 34.6 & 24.6 & 25.1 & 21 & 27.4 & 25.1 & 26.0 & 21.7 & 22.2 & 28.3 & \\
\hline $\mathrm{BE}$ (mmHg) & 0.5 & 1.5 & 2 & 1.06 & 2.8 & -2.5 & 5.0 & 2.6 & 2.5 & -0.8 & -0.6 & 0.7 & \\
\hline $\mathrm{FiO}_{2}$ & & 0.6 & 0.5 & & & & 0.6 & 0.6 & 0.6 & 0.35 & 0.3 & 0.3 & \\
\hline $\mathrm{Na}^{+}(\mathrm{mmol} / \mathrm{L})$ & 136 & 139 & 136 & 134 & 135 & 134 & 141 & 142 & 143 & 140.6 & 135 & 133 & \\
\hline $\mathrm{K}^{+}(\mathrm{mmol} / \mathrm{L})$ & 4.8 & 3.46 & 3.76 & 2.88 & 5.21 & 4.08 & 4.30 & 4.13 & 4.09 & 4.11 & 4.01 & 3.93 & \\
\hline $\mathrm{Ca}^{2+}(\mathrm{mmol} / \mathrm{L})$ & 0.96 & 1.17 & 1.18 & 1.05 & 1.39 & 1.08 & 1.30 & 1.13 & 1.09 & 1.02 & 1.11 & 1.11 & \\
\hline $\mathrm{Mg}^{2+}(\mathrm{mmol} / \mathrm{L})$ & 0.41 & 0.6 & 0.58 & 0.50 & 0.80 & 0.65 & 0.68 & 0.61 & 2.56 & 0.49 & 0.54 & 0.55 & \\
\hline Lactate (mmol/L) & 0.6 & & & & 1.6 & & 2.0 & 1.6 & 1.1 & 0.9 & 1.3 & 1.6 & \\
\hline Glucose (mg/dl) & 134 & 108 & 118 & 274 & 274 & & 285 & 285 & 286 & 156 & 208 & 174 & \\
\hline Osmorality (mOsm) & & 277 & 278 & 274 & 274 & & 285 & 285 & 286 & & & & \\
\hline BUN (mg/dl) & & 8 & 9 & 8 & 9 & 1 & 9 & 8 & 8 & & & & \\
\hline
\end{tabular}

Preop: preoperative, Postop: postoperative, Pre-CPB: period before the initiation of cardiopulmonary bypass, CPB: during the cardiopulmonary bypass, Post-CPB: period after the weaning from the cardiopulmonary bypass. PT: prothrombin time, APTT: activated partial thromboplastin time, BE: base excess, BUN: blood urea nitrogen. 


\section{Discussion}

The advantage of ANH is that it reduces blood viscosity. ANH improves microcirculation in patients in whom the blood viscosity increases due to severely low body temperature, as in the present case [8]. However, cardiovascular ischemia may

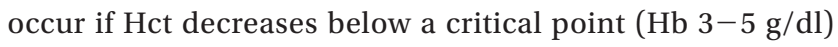
[2]. In a retrospective analysis of patients who refused a blood transfusion for religious reasons [9], those with a $\mathrm{Hb}$ of 4-5 $\mathrm{g} / \mathrm{dL}$ had a $34.4 \%$ mortality rate and a $57.7 \%$ rate of serious side effects, such as myocardial infarction, arrhythmia, and cardiac failure. For every $1 \mathrm{~g} / \mathrm{dl}$ reduction in $\mathrm{Hb}$ from $8 \mathrm{~g} / \mathrm{dl}$, the incidence of side effects increases 2.5 times. When $\mathrm{Hb}$ drops below $5-6 \mathrm{~g} / \mathrm{dl}$, the patient is at the highest level of danger. This provides a good reference point for determining the $\mathrm{Hb} / \mathrm{Hct}$ target level during anesthetic management of a JW patient.

Surgeries requiring a long period of DHCA, as in the present case, necessitate quite a large volume of ANH blood to treat hemorrhaging in the latter half of the surgery. After activating CBP, we targeted the Hct at $20 \%$ [10] and planned to salvage $1,800 \mathrm{ml}$ of ANH blood. However, when 1,500 ml of ANH blood was salvaged, the $\mathrm{rSO}_{2}$ suddenly dropped below $55 \%$. So, we stopped ANH (immediately after stopping ANH, the Hct was $22 \%$ ) because we considered that a reduction below the absolute value of $50 \%$ or a reduction of more than $20 \%$ of the safe range was an abnormal symptom of $\mathrm{rSO}_{2}$ in a patient with carotid artery stenosis [11].

Also, the possibility of exacerbated hemodilution was considered, which often occurs once CBP is activated. Moreover, when perfusion pressure is maintained by vasoconstrictors, as it was in the present case, RBCs are sequestered in the extremities, so $\mathrm{rSO}_{2}$ may appear rather low. In such cases, if the circulating blood volume is increased with fluids, one must consider that $\mathrm{rSO}_{2}$ could have risen despite the fact that Hct systemically becomes more diluted and decreases. Monitoring $\mathrm{rSO}_{2}$ may be more useful when a CBP circuit is activated and does not have a blood oxygen saturation or Hct monitor sensor attached. Even in the presented case, continuous $\mathrm{rSO}_{2}$ monitoring helped with the early discovery of sudden hemodilution.

We collected 1,500 $\mathrm{ml}$ of ANH blood in three CPD bags. The elapsed time from the repetition of $\mathrm{ANH}$ and simultaneous blood infusion caused dilution and a reduction in the RBC and plasma components. Therefore, each time ANH is performed, the retrieved ANH blood should be marked to identify the retrieval time before storage. The correct choice of ANH-blood among the retrieved blood fractions should be made according to the situation.

ICS washing is required due to massive hemorrhaging, which causes damage to plasma components (excluding RBCs) and exacerbates the likelihood of hemorrhaging. When all blood collected by ICS is completely infused, the blood salvaged last, which contains the lowest relative levels of $\mathrm{Hb}$, platelets, and other coagulation factors, should be infused first. Immediately before the surgery ends, the ANH-blood collected at the beginning with relatively high content levels should be infused, which will help restore coagulation and hemostasis.

Other than $\mathrm{rSO}_{2}$ monitoring, constantly monitoring circulating plasma and heart function by monitoring TEE, central venous pressure, pulmonary arterial pressure, APCO, and SVV is very important. In addition, determining the systemic oxygen supply-consumption balance by monitoring $\mathrm{SvO}_{2}$ and lactate is also imperative. Monitoring hemodynamics is helpful especially when adjusting the blood salvaging machine's activation rate, the infusion rate of the retrieved ICS-blood, and the fluid administration rate. Determining the intravascular volume status is also helpful.

During ANH hemodilution, the intravascular protein level is reduced, causing changes in intravascular osmolarity, which causes fluid movement into the lung interstitial tissue. In serious cases, it results in pulmonary edema, hypoxia, and reduced oxygen-carrying capacity. This increases danger and the need for a transfusion. To prevent this, albumin, electrolytes, osmotic pressure, and the arterial oxygen tension/administered oxygen concentration ratio in the blood must be monitored and maintained at the beginning of surgery, as in the present case (Table 1). It is important not to administer crystalloid solution excessively. Furthermore, applying positive end-expiratory pressure, which can reduce pulmonary damage and protective ventilation, is useful.

Administering EPO before surgery is recommended for increasing erythropoietic ability and RBC mass [3]. In the present case, the likelihood of AAA rupture was high and required emergency surgery, so it was most likely that not enough EPO was administered and the full effects of the medication were not attained.

The use of CPB and various maneuvers during surgery cause inflammation and increase the likelihood of hemorrhaging. To prevent this, we administered transxanemic acid [12] and a urinary trypsin inhibitor. Although the recombinant activated Facto VIIa [13] is useful for successfully managing anesthesia in JW patients, we did not use it in the present case. Because the limited use of a cryoprecipitate is helpful in JW patients, its administration was considered for use by patient agreement in the presented case [13], but it was not administered due to a satisfactory coagulation profile.

In conclusion, $\mathrm{rSO}_{2}$ monitoring was useful for determining the timing for administering ICS- and ANH-blood when ANH and ICS were applied during AAA surgery in a JW patient. 


\section{References}

1. Despotis GJ, Filos KS, Zoys TN, Hogue CW Jr, Spitznagel E, Lappas DG. Factors associated with excessive postoperative blood loss and hemostatic transfusion requirements: a multivariate analysis in cardiac surgical patients. Anesth Analg 1996; 82: 13-21.

2. Hughes DB, Ullery BW, Barie PS. The contemporary approach to the care of Jehovah's witnesses. J Trauma 2008; 65: 237-47.

3. Pasic M, Ruisz W, Koster A, Hetzer R. Bloodless surgery of acute type A aortic dissection in a Jehovah's Witness patient. Ann Thorac Surg 2005; 80: 1507-10.

4. Torella F, Cowley R, Thorniley MS, McCollum CN. Monitoring blood loss with near infrared spectroscopy. Comp Biochem Physiol A Mol Integr Physiol 2002; 132: 199-203.

5. Torella F, Haynes SL, McCollum CN. Cerebral and peripheral oxygen saturation during red cell transfusion. J Surg Res 2003; 110: 217-21.

6. Kim SH, Kim TY, Lee HH, Yoon TG. Cerebral oxygen saturation monitoring for off-pump coronary bypass graft surgery with Moyamoya disease -A case report- Korean J Anesthesiol 2009; 56: 433-7.

7. Kim MB, Ward DS, Cartwright CR, Kolano J, Chlebowski S, Henson LC. Estimation of jugular venous $\mathrm{O}_{2}$ saturation from cerebral oximetry or arterial $\mathrm{O}_{2}$ saturation during isocapnic hypoxia. J Clin Monit Comput 2000; 16: 191-9.

8. Licker M, Ellenberger C, Sierra J, Kalangos A, Diaper J, Morel D. Cardioprotective effects of acute normovolemic hemodilution in patients undergoing coronary artery bypass surgery. Chest 2005; 128: 838-47.

9. Carson JL, Noveck H, Berlin JA, Gould SA. Mortality and morbidity in patients with very low postoperative $\mathrm{Hb}$ levels who decline blood transfusion. Transfusion 2002; 42: 812-8.

10. Helm RE, Klemperer JD, Rosengart TK, Gold JP, Peterson P, DeBois $\mathrm{W}$, et al. Intraoperative autologous blood donation preserves red cell mass but does not decrease postoperative bleeding. Ann Thorac Surg 1996; 62: 1431-41.

11. Edmonds HL Jr, Ganzel BL, Austin EH 3rd. Cerebral oximetry for cardiac and vascular surgery. Semin Cardiothorac Vasc Anesth 2004; 8: 147-66.

12. Moskowitz DM, Perelman SI, Cousineau KM, Klein JJ, Shander A, Margolis EJ, et al. Multidisciplinary management of a Jehovah's Witness patient for the removal of a renal cell carcinoma extending into the right atrium. Can J Anaesth 2002; 49: 402-8.

13. Haan J, Scalea T. A Jehovah's Witness with complex abdominal trauma and coagulopathy: use of factor VII and a review of the literature. Am Surg 2005; 71: 414-5. 